\title{
Study of mechanical behavior by fatigue of a cracked plate repaired by different composite patches
}

\author{
Moulgada Abdelmadjid \\ LRI, Department of Mechanical Engineering, University of Ibn Khaldoun Tiaret, City Zaaroura BP 7814000 Tiaret, Algeria \\ amoulgada@hotmail.fr
}

\author{
Ait kaci Djafar, Sahli Abderrahmane \\ Department of Mechanical Engineering, University of Djillali Liabes Sidi Bel Abbes, Algeria \\ Aitkaci07@yahoo.fr,sabliabderahmen@yahoo.fr
}

\section{Zagane Mohammed El Sallah}

Department of Mechanical Engineering, University of Ibn Khaldoun Tiaret, City Zaaroura BP 7814000 Tiaret, Algeria salab_cao@yahoo.fr

\section{Zahi Rachid}

Department of Mechanical Engineering, University of Ahmed Zabana Relizane 48000, Algeria zabirachid72@yahoo.fr

\begin{abstract}
This research is based on the study of the fatigue behavior of an aluminum alloy plate with a central crack. The plate is subjected to a tensile loading on its lower and upper parts. Several parameters were highlighted, such as the loading effect with a load ratio $\mathrm{R}=0$. The effects of the load ratio on both the repaired and not repaired plates, by two composite patches, which are boron/epoxy and graphite/epoxy, were investigated, as well as the effect of the plate material on plate life, comparing different materials.
\end{abstract}

KEYwORDS. Fatigue; Crack; Composite patch; Load ratio.

\section{OPEN $\odot$ ACCESS}

Citation : Moulgada, A, Ait kaci, D., Sahli., A, Zagane, M.E, Zahi, R., Study of Mechanical Behavior by Fatigue of a Cracked Plate Repaired by Different Composite patches. Frattura ed Integrità Strutturale, 56 (2021) 195-202.

Received: 08.02.2021

Accepted: 15.03 .2021

Published: 01.04.2021

Copyright: (C) 2021 This is an open access article under the terms of the CC-BY 4.0, which permits unrestricted use, distribution, and reproduction in any medium, provided the original author and source are credited. 


\section{INTRODUCTION}

$\mathrm{T}$

he study of the propagation of fatigue cracks in structures depends on the nature of the applied loads (constant amplitude loading). These loadings are characterized by several parameters, whose influences on the fatigue life and the cracking rate are very significant from the point of view of the mechanical integrity of the structures. Constant amplitude loading is characterized by the stress amplitude and the load ratio. Several parameters/factors of a cracked thin aluminum plate with bonded composite patch were considered. These were strain distribution, out-of-plane deformation, and residual strength, including the investigation of fatigue crack; growth behavior for thin plates repaired with composite patches, the characterization of crack retardation in thin plates after the repair, and the examination of debondinge growth [1]. In addition, the investigation of [2] focused on the response of cracked steel specimens repaired by polymer composite patches on single sides of the specimens subjected to tensile and bending loadings and hardness test. The un-cracked and patched specimens were tested in the above loading conditions and the test results were evaluated by analyzing the effect of patch thickness and patch materials. A fatigue experimental study to characterize the effect of Carbon Fiber Reinforced Polymer (CFRP) strengthening patches on the fatigue strength of aluminum alloy plates with fastener holes was carried out in [3]. Three CFRP strengthening schemes were reported and the corresponding typical failure modes and fractographic patterns were discussed in detail. The investigation from the experimental, numerical, and analytical points of view for crack growth of CFRP-strengthened steel plates single edge notched tension (SENT) specimens, reinforced on a single side by using CFRP strips, was considered. Other reinforcing configurations are worth investigation, such as the crack emanating from the lateral side of the tension flange of a steel beam under cyclic bending loading [4]. A numerical simulation on a laterally cracked plate, repaired by two composite patches, namely boron/epoxy and carbon/epoxy, was proposed in [5]. The fatigue life and fatigue crack growth rates of $10 \mathrm{~mm}$ thick aluminum panels repaired with two-sided bonded patches were evaluated in [6]; also, the stress intensity factor (SIF) values of the patched plates and the fatigue life prediction of two-sided repaired plates were investigated by using the 3-D finite element method (FEM). The study of static analysis for different patch shapes like circle, rectangle, square, ellipse, and octagon was considered. Performance comparison of bonded repair was done by analyzing SIF reduction at the crack tip for double-sides patch model in [7]. Naboulsi et al. [8] introduced the three-layer technique into the finite element analysis to model a cracked metallic plate repaired with a bonded composite patch. In [9], the fatigue lives of four drilling hole procedures were compared and the role of the residual compressive stresses introduced by each drilling process on the fatigue behavior of $2024-\mathrm{T} 3$ aluminum alloy was shown. In [10] a new geometry used for stop-hole was proposed, in which instead of a single hole, two symmetric and interconnected holes were drilled at the crack tip. The main concept of double stop-hole method is to diminish the stress singularity at the crack tip and to reduce the stress concentration at the edge of stop-holes in the cracked structural elements. A numerical study of fatigue cracks behavior damaged aeronautical structures repaired by composite was presented. Various parameters were highlighted, such as the effect of the dimensions, the orientation of the fibers, and the mechanical properties of the patch, as well as the effect of the dimensions and the mechanical properties of the adhesive [11]. The SIF for patched crack exhibits an asymptotic behavior as the crack length increases. This is due to the stress transfer toward the composite patch throughout the adhesive layer [12-13]. In addition, in [14] many desirable characteristics and the enforcement of the SQ4C element were verified and proved through various numerical examples in static, frequency, and buckling analyses of laminated composite plates and shell structures.

This study is focused on an aluminum alloy plate, presenting a central crack, subjected to tension on its upper and internal parts by cyclic loadings, to investigate the fatigue behavior of this plate. Loads of different amplitudes were considered, thus varying the load ratio between the minimum and maximum stress, and, in the end, the analyzed material was varied to see, among the proposed materials, the one that was the most resistant for these stresses. This plate was stressed either without repair and with repair with two different composite patches, namely boron/epoxy and graphite/epoxy.

\section{Forman / Mettu (Nasgro) Model}

The NASGRO model, used in the prediction of the fatigue cracking propagation rate and implemented in several fatigue calculation codes, was developed and modified by Maierhofer et al. [14]. The NASGRO model predicts the cracking rate for the 3D domains, and it is in the form:

$$
\frac{d a}{d N}=C\left[\left(\frac{1-f}{1-K}\right) \Delta K\right]^{n} \frac{\left(1-\frac{\Delta K c b}{\Delta K}\right)^{p}}{\left(1-\frac{K \max }{\text { Krit }}\right)^{q}}
$$




$$
\text { Load ratio } \quad \mathrm{R}=\frac{\sigma \min }{\sigma \max }
$$

the coefficients C, n, p, q are empirical parameters, while Kmax and Kcrit are respectively the maximum stress intensity factor and the critical stress intensity factor.

The parameters required for the NASGRO equation are in Tab. 1.

\begin{tabular}{llllllll}
\hline Materials & $\mathrm{C}\left(10^{-3}\right)$ & $\mathrm{P}$ & $\mathrm{N}$ & $\mathrm{q}$ & $\Delta \mathrm{K}$ & $\mathrm{E}(\mathrm{GPa})$ & $\nu$ \\
& & & & & & & \\
2024-T3 & 6.827 & 2.8 & 0.5 & 1 & 2.967 & 73.08 & 0.33 \\
2024-T62 & 7.454 & 2.657 & 0.5 & 1 & 3.956 & 73.08 & 0.33 \\
2024-T861 & 5.4 & 2.92 & 0.2 & 1 & 2.417 & 73.08 & 0.33 \\
\hline
\end{tabular}

Table 1: Different parameters of NASGRO equation for different materials.

\section{Presentation of the model}

As visible in Fig. 1, the aluminum alloy plate has the following dimensions: length $\mathrm{L}=200 \mathrm{~mm}$, width $\mathrm{W}=102 \mathrm{~mm}$, and thickness $\mathrm{E}=2.3 \mathrm{~mm}$, while the length of the crack is $\mathrm{a}=2 \mathrm{~mm}$. The materials chosen for this simulation are aluminum alloys, such as 204-T3, 2024-T62 and 2024-T861.

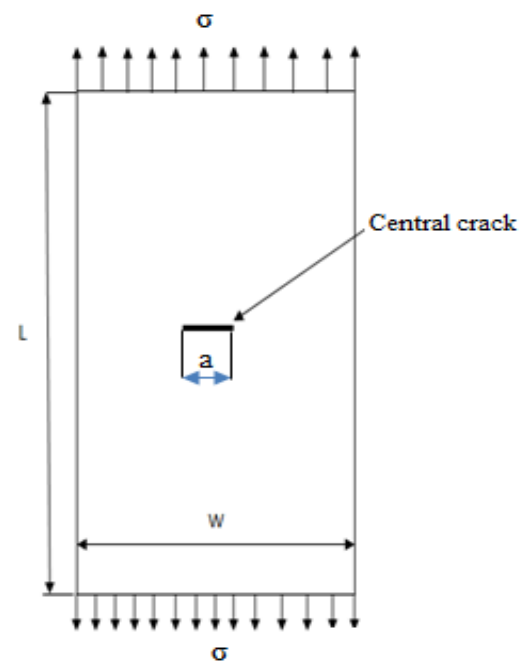

Figure 1: Presentation of the model

\section{Properties of the Patch}

The composites used for the repair are graphite-epoxy and boron-epoxy, and the relevant mechanical properties are reported in Tab. 2. The laminate consists of 12 plies of a unidirectional composite material, the thickness of each ply is $0.132 \mathrm{~mm}$, and the stacking sequence is as follows: $\left[-45^{\circ}, 0^{\circ}, 0^{\circ}, 90^{\circ}, 0^{\circ},+45^{\circ}\right]_{\mathrm{s}}$

\begin{tabular}{llcl}
\hline Composite & $\mathrm{E}_{\mathrm{L}}(\mathrm{GPa})$ & $\mathrm{E}_{\mathrm{T}}(\mathrm{MPa})$ & $\mathrm{G}_{\mathrm{LT}}(\mathrm{MPa})$ \\
Boron/epoxy & 6.827 & 2.8 & 0.5 \\
Graphite/Epoxy & 7.454 & 2.657 & 0.5 \\
\hline
\end{tabular}

Table 2: Properties of composite patch. 
The FM-73 adhesive is used, with a shear modulus $\mathrm{G}_{\mathrm{LT}}=413.368 \mathrm{MPa}$, and a thickness of $0.1524 \mathrm{~mm}$. For the studied case, the applied constraint is $\sigma \max =100 \mathrm{MPa}$.

\section{RESULTS AND DISCUSSIONS}

\section{Effect of variation of loading}

Material: AL 2024 T3

Ig. 2 shows the variation of the crack length as a function of the service life for the plates repaired by the two different composites and the not repaired plate, for different loading levels and a zero load ratio $(\mathrm{R}=0)$. It is noted that the effect of the repair is very distinct, and the life of the repaired plate is enhanced for every load level.

As an effect of the loading level on the plate with a load ratio $\mathrm{R}=0$, the four graphs indicate that the life of the plate is inversely proportional to the load, that is to say as the load is increased, the service life automatically decreases, and vice versa.

In all the loading cases, the graphite/epoxy composite has a better performance with respect to the fatigue life for the repair, either for the absorption of the stresses at the head of the crack, and the prolongation of its life. However, the repair by the bore/epoxy composite; also gives long life to the plate.
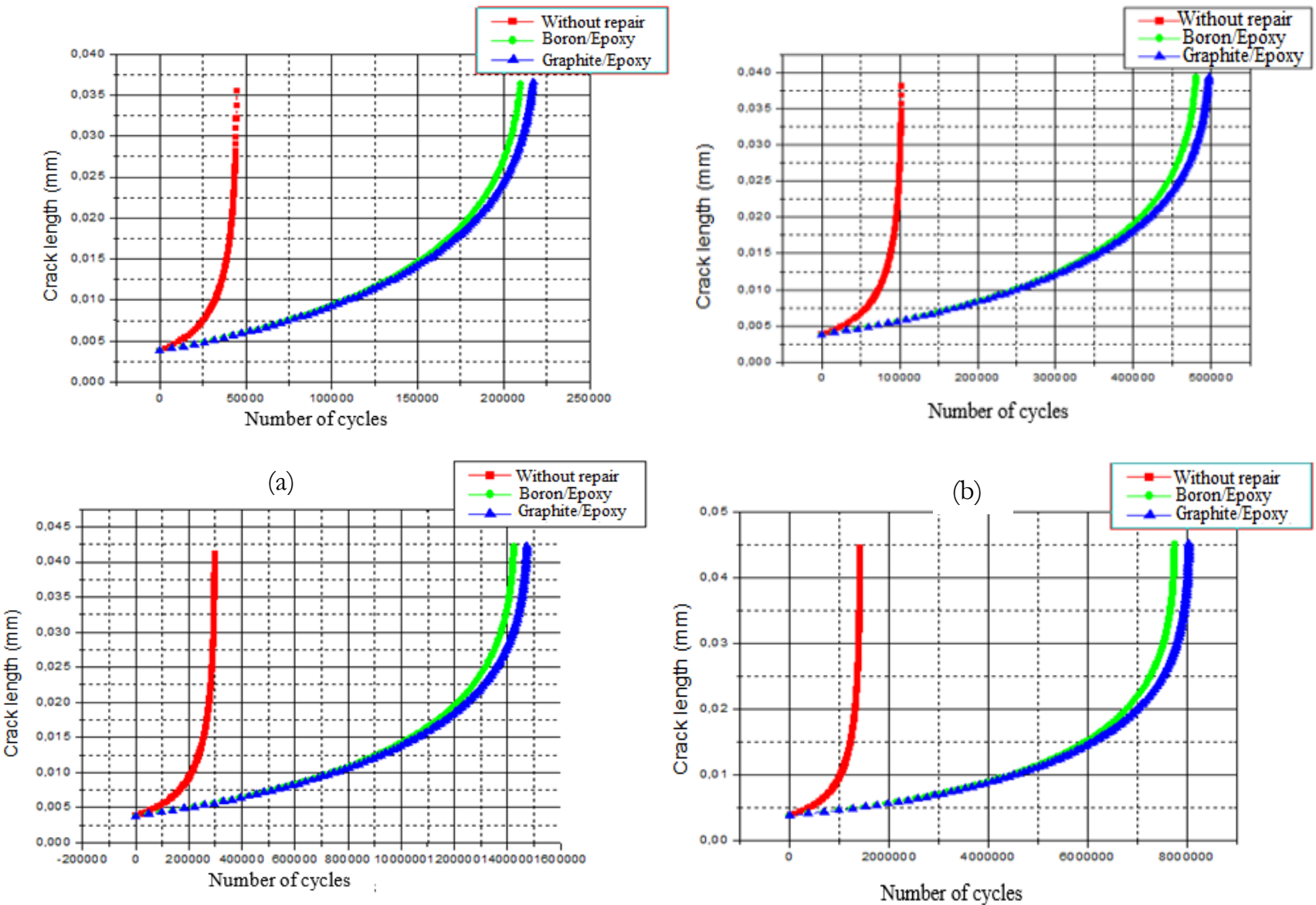

Figure 2: Variation of the crack propagation as a function of the number of cycles for the not repaired plate and repaired by boron/ epoxy and graphite/epoxy: (a) $\mathrm{P}=100 \mathrm{MPa}$, (b) $\mathrm{P}=80 \mathrm{MPa}$, (c) $\mathrm{P}=60 \mathrm{MPa}$ and (d) $\mathrm{P}=40 \mathrm{MPa}$.

\section{Effect of the load ratio}

Fig. 3 shows the crack propagation trend as a function of the number of cycles of the unrepaired and repaired plates for the different load ratios $(\mathrm{R}=0.2,0.4$ and 0.6 ), considering a single load level (80 MPa). It is noted that as the load ratio 
increases, the service life of the plate cracked and repaired by the two composite patches also increases, so the load ratio is strictly proportional to the life of the plate. Also, the effect of composite repair on the life extension of the cracked plates can be distinguished.
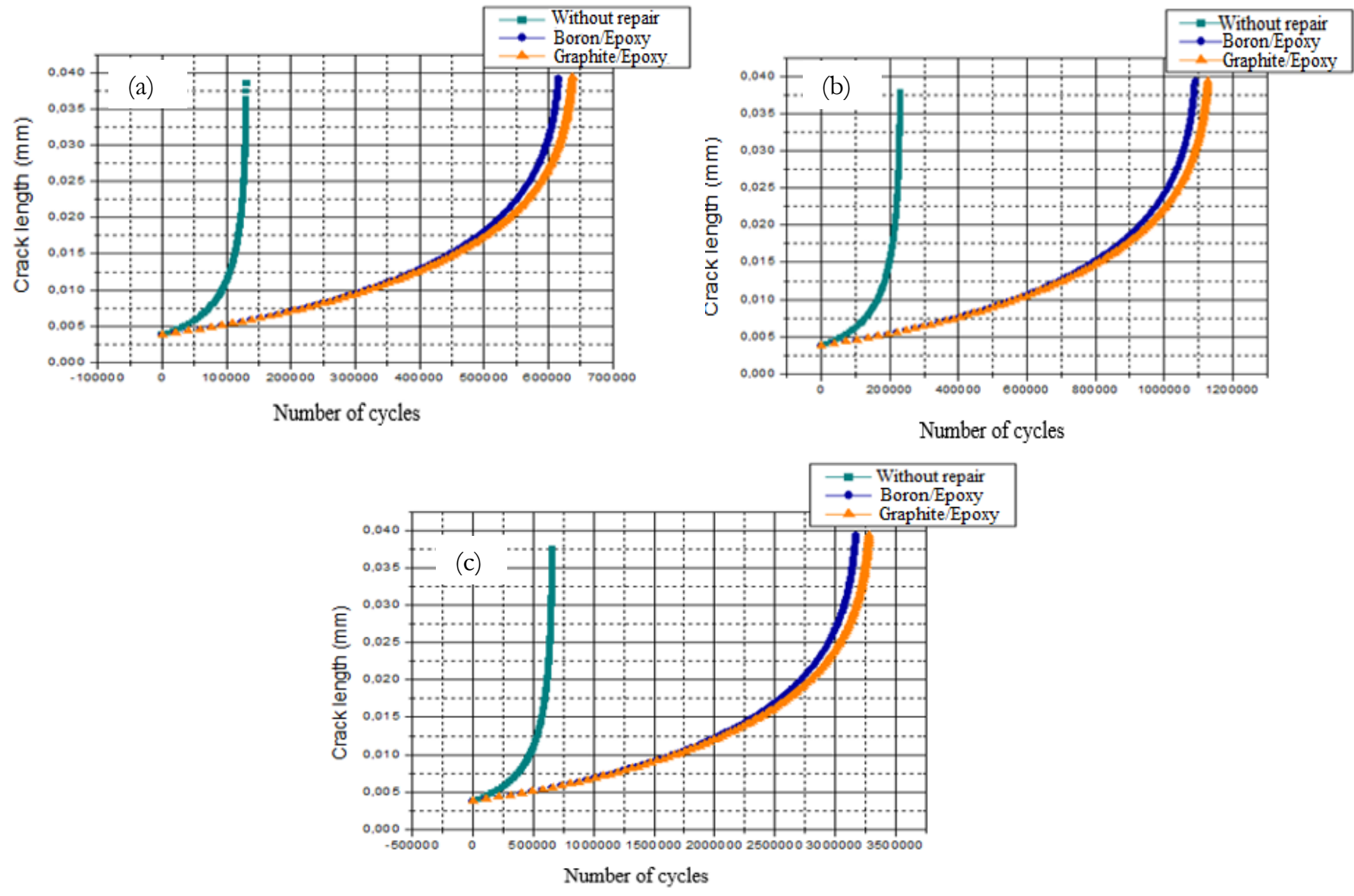

Figure 3: Variation of crack propagation according to the number of cycles for the unrepaired and repaired plate by boron/epoxy and graphite/epoxy for: (a) $\mathrm{R}=0.2$, (b) $\mathrm{R}=0.4$ and (c) $\mathrm{R}=0.6$.

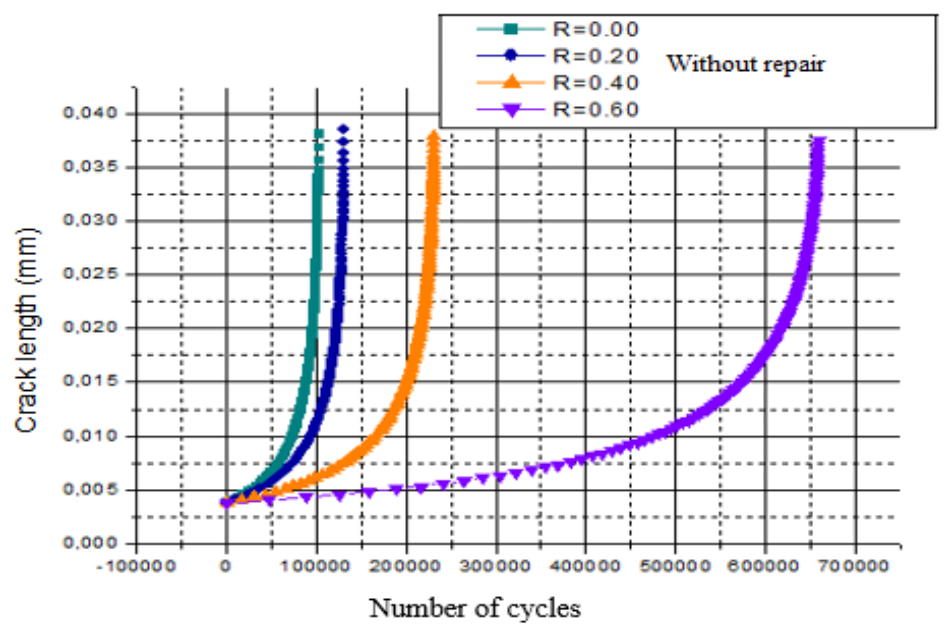

Figure 4: Effect of load ratio on fatigue life for unrepaired plate. 
Fig. 4 shows the evolution of the crack length "a" as a function of the number of cycles "N" under the effect of the load ratio " $\mathrm{R}$ ". The increased load ratio increases the service life; this is in fact due to the decrease in the loading amplitude " $\Delta \sigma$ ": at $\mathrm{R}=0$, the loading amplitude is $100 \mathrm{MPa}$, on the other hand at $\mathrm{R}=0.2$ the loading amplitude is $80 \mathrm{MPa}$.

It is noted at $\mathrm{R}=0$, the fatigue life is $10^{5}$ cycles. At $\mathrm{R}=0.2$; the service life is 125,000 cycles, for $\mathrm{R}=0.4$ the loading amplitude is $60 \mathrm{MPa}$, while the fatigue life is 235,000 cycles and for $\mathrm{R}=0.6$, the loading amplitude is $40 \mathrm{MPa}$.

It is concluded that the increase in the life of a material is strictly proportional to the increase in the load ratio, i.e. with the increase in minimum stress.

To study the effect of the load ratio on the fatigue life of the plate, repaired by the boron/epoxy patch, Fig. 5 shows the variation of the crack length as a function of the service life for different load ratios. It is noted that the effect of the repair is very distinct and the life of the repaired plate is simultaneously progressed for every load; it is of the order of $35 \cdot 10^{5}$ cycles for $\mathrm{R}=0.6$, about $11.6 \cdot 10^{5}$ cycles for $\mathrm{R}=0.4 ; 1.7 \cdot 10^{5}$ cycles for $\mathrm{R}=0.2$ and $4.8 \cdot 10^{5}$ cycles for $\mathrm{R}=0$.

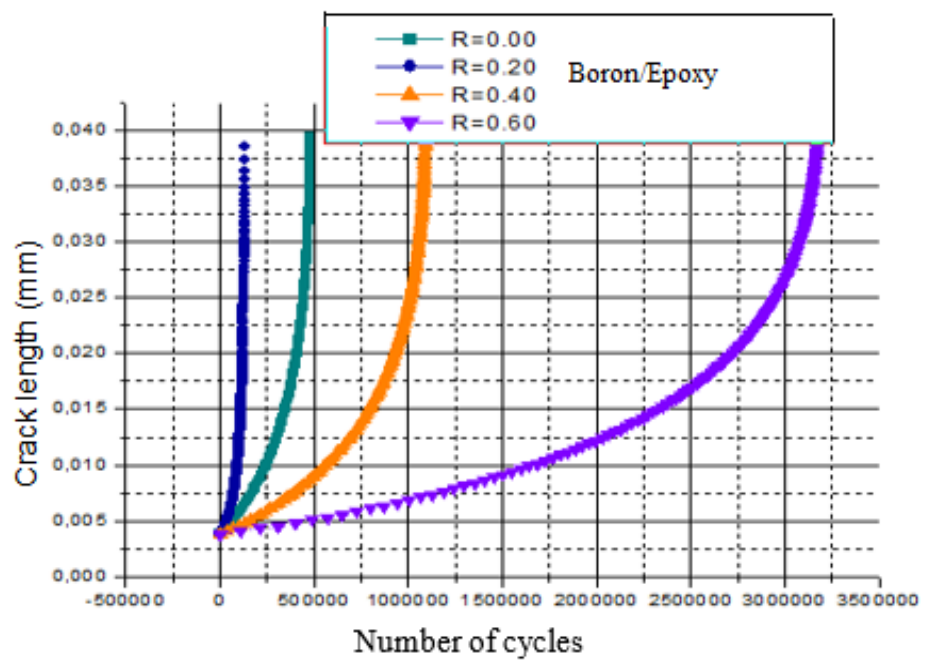

Figure 5: Effect of load ratio on fatigue life for the plate repaired by the boron/epoxy patch.

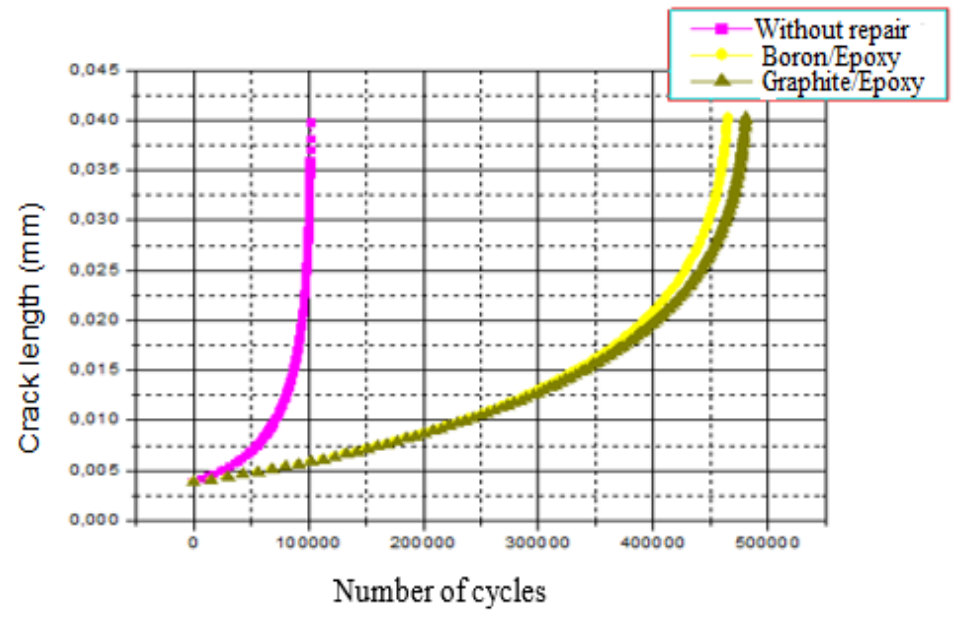

Figure 6: Effect of AL 2024-T62 material on the variation of the service life for the unrepaired and repaired plate by boron/epoxy and graphite/epoxy.

\section{Effect of material}

Aluminum alloy 2024-T62 (For $\mathrm{P}=80 \mathrm{MPa}$ and $\mathrm{R}=0$ )

For the effect of 2024-T62 aluminum alloy, the variation of the crack propagation life for the unrepaired and repaired plates by boron/epoxy and graphite/epoxy, for the load ratio $\mathrm{R}=0$, is shown in Fig. 6 . It is very distinct in view of the best properties of composite patches for repairing and absorbing stresses. These patches improve and increase the life of these plates, which can reach approximately $4.6 \cdot 10^{5}$ cycles for boron/epoxy and $4.8 \cdot 10^{5}$ cycles for graphite/epoxy. 
Aluminum alloy 2024-T861

For the effect of the AL 2024-T861 material, the variation of the crack propagation life for the unrepaired and repaired plate by boron/epoxy and graphite/epoxy is shown in Fig. 7. For the unrepaired plate, the number of cycles is $0.4 \cdot 10^{5}$ cycles, for the boron/epoxy patch it is approximately $2 \cdot 10^{5}$ cycles and finally for the graphite/epoxy it is approximately $2.25 \cdot 10^{5}$ cycles. Therefore, the repair by the two composite patches is very significant, and the life of the plate is relative to the mechanical properties of each material.

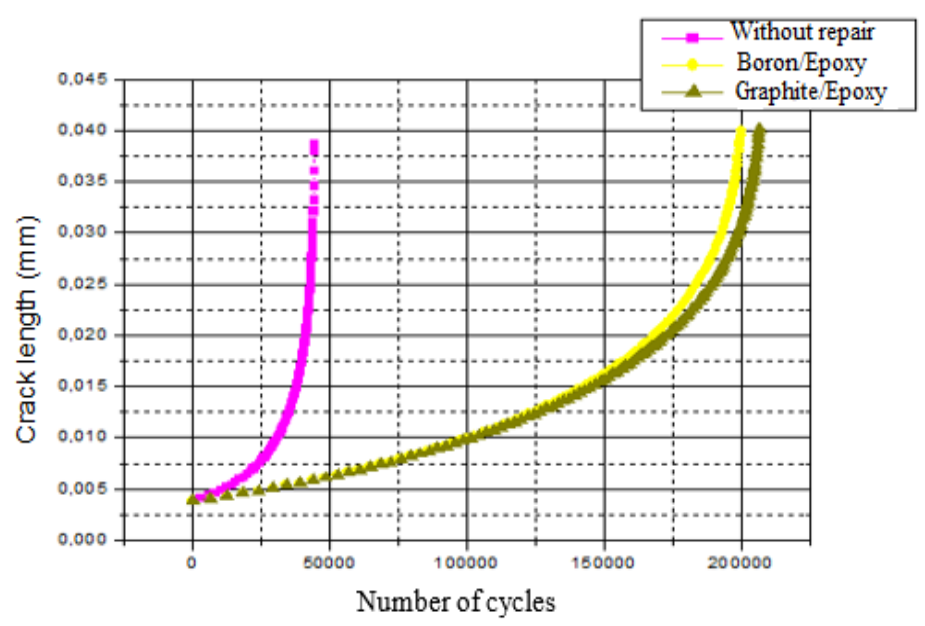

Figure 7: Effect of AL 2024-T861 material on the propagation of crack for the unrepaired and repaired plate by boron/epoxy and graphite/epoxy.

\section{Aluminum alloy 2024-T3}

Regarding the effect of the AL 2024-T3; material on the variation of the service life, for the plate not repaired and repaired by boron/epoxy and graphite/epoxy, also in this case the graphite/epoxy is a better repair solution, given the increase in the life of the cracked and repaired plate, which reached $5 \cdot 10^{5}$ cycles, while the boron/epoxy repair achieved a number of cycles of approximately $4.8 \cdot 10^{5}$ cycles.

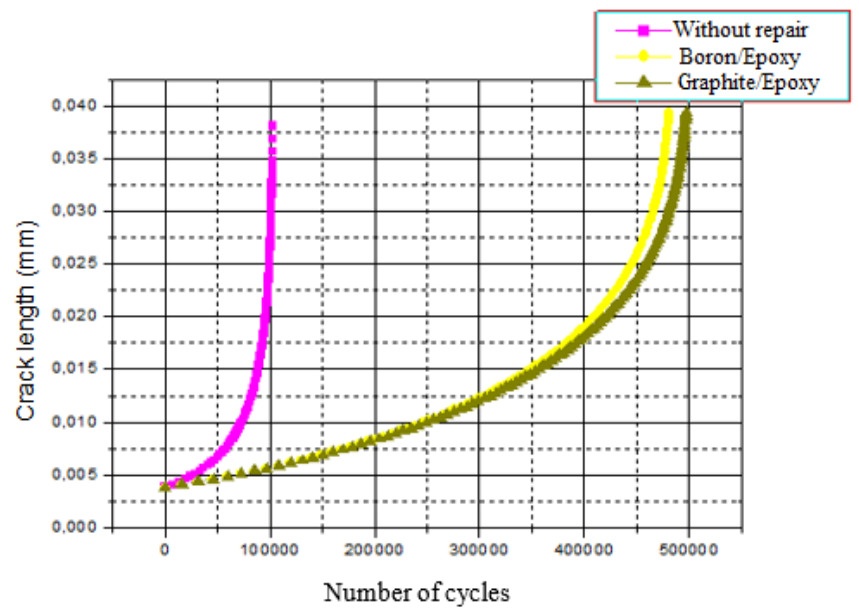

Figure 8: Effect of AL 2024-T3 material on the variation of the service life for the plate not repaired and repaired by boron/epoxy and graphite/epoxy.

\section{CONCLUSION}

7 he use of the composite patch for repair absorbs the stresses induced from the damaged area through the adhesive, also reduces stress at the crack tip and improves the mechanical properties of the structure. It can be said that the patch considerably increases the strength of the plate as well as its rigidity to ensure a long fatigue life of the structure and it retards the progression of cracks for long use. 
For the effect of loading on the plate with a load ratio $\mathrm{R}=0$, the life of the plate is inversely proportional to the loading level, that is to say; as the load is increased, the service life automatically decreases.

For the variation of the crack propagation as a function of the number of cycles; for the plates unrepaired and repaired by boron/epoxy and graphite/epoxy, for the different load ratios $(\mathrm{R}=0.2 ; 0.4$ and 0.6$)$, the life of the plate is strictly proportional to the load ratio, and also the effect of composite repair on the prolongation of the cracked plate life can be distinguished.

For the different materials of the cracked plate, the graphite/epoxy composite presents a better repair solution, increasing the life of this plate, given its more efficient mechanical properties compared to the boron/epoxy composite.

\section{REFERENCES}

[1] Sabelkin, V., Hansen, S., Vandawaker, R.M. (2007). Investigation into cracked aluminum plate repaired with bonded composite patch. Composite Structures 79, pp. 55-66.

[2] Pradhan, S.S., Mishra, U., Biswal, S.K. (2020). Experimental study on mechanical performance of cracked aluminium alloy repaired with composite patch. Materials Today: Proceedings. Elsevier 26, pp. 2676-2680.

[3] Wanga, Z.Y., Zhanga, T. L., Xiaolei, W., Huang, Q.Y. and Shen, W. M. (2018) Characterization of the effect of CFRP reinforcement on the fatigue strength of aluminium alloy plates with fastener holes. Engineering Structures: Elsevier 177, pp. 739-752.

[4] Colombi, P., Fava, G. and Sonzogni, L. (2015). Fatigue crack growth in CFRP-strengthened steel plates. Composites Part B: Engineering, 72, pp. 87-96.

[5] Moulgada, A., Zagane, E. M., Sahli, A., Ait kaci, D. and Zahi, R. (2020). Comparative study of the repair of cracked plates with two different composite patches. Frattura ed Integrità Strutturale, 14, pp. 187-201.

[6] Jian-Bin, H., Xu-Dong, L., Zhi-Tao, M. (2015). Fatigue behavior of thick center cracked aluminum plates repaired by two-sided composite patching." Materials \& Design 88, pp. 331-335.

[7] Ramji, M., Srilakshmi. R. and Prakash, B.M. (2016). Towards optimization of patch shape on the performance of bonded composite, repair using FEM. Composites Part B: Engineering, 45, pp. 710-720.

[8] Naboulsi, S., \& Mall, S. (1996). Modeling of a cracked metallic structure with bonded composite patch using the three-layer technique. Composite Structures, 35, pp. 295-308.

[9] Elajrami, M., Benguediab, M., Guillen, R. (2008). Effect of various drilling procedures on the fatigue life of rivet hole. Sciences and Technologie.

[10] Ayatollahi, M. R., Razavi, S. M. J., Sommitsch, C. and Moser, C. (2016). Fatigue Life Extension by Crack Repair Using Double Stop-Hole Technique. Materials Science Forum 879, pp. 3-8.

[11] Achache, H., Ait Kac1, D., Moulgada, A. (2018). Numerical Analysis of the Behavior of Structures Damaged by Fatigue and Repaired by Composite Patch. The Eurasia Proceedings of Science Technology Engineering and Mathematics, pp. 35-42.

[12] Fekirini, H., Bachir Bouiadjra, B., Belhouari, M., Boutabout, B., Serier, B. (2008). Numerical analysis of the performances of bonded composite repair with two adhesive bands in aircraft structures. Composite structures 82 , pp. 84-89.

[13] Bachir Bouiadjra, B.B., Fekirini, H., Serier, B., Belhouari, M., and Benguediab, M. (2008). Energy Release Rate for Repaired Inclined Cracks with Bonded Composite Patch Having Two Adhesive Bands in Aircraft Structures. Journal of reinforced plastic and composites 28, pp. 1135-1146.

[14] Ton-That, H. L., Nguyen-Van, H. (2021). A Combined Strain Element in Static, Frequency and Buckling Analyses of Laminated Composite Plates and Shells. Periodica Polytechnica Civil Engineering, 65, pp. 56-71.

[15] Maierhofera, b., Pippanb, R., Gänser, H.P. (2014). Modified NASGRO equation for physically short cracks, International Journal of Fatigue 59, pp. 200-207. 